\title{
The Effect of GeoGebra-Based Learning on Students Spatial Ability and Motivation
}

\author{
V N Yulian ${ }^{1}$, Wahyudin $^{2}$, Lela Anggrayani ${ }^{3}$ \\ \{varanina15@student.upi.edu ${ }^{1}$, wahyudin.mat@upi.edu ${ }^{2}$ \}
}

Study Program of Mathematics Education, School of Postgraduate Studies,Universitas Pendidikan Indonesia, Jl. Dr. Setiabudhi 229, Bandung, Indonesia ${ }^{1,2}$, Study Program of Mathematics Education, Universitas Subang, Jl. RA Kartini Km 3 Subang, Subang, Indonesia ${ }^{1,3}$

\begin{abstract}
The aims of this study are identifying differences between the application of GeoGebra-based learning and Non-GeoGebra on the spatial abilities of students in Geometry Transformation, identifying difference between learning motivation categories and students' spatial ability and identifying differences the effect of interaction between GeoGebra based learning and motivation on students' spatial abilities. The subject in this research was 60 students from 20 classes. Data collection was carried out by taking a questionnaire for learning motivation data and spatial abilities test. The results of the study show the spatial abilities of students with GeoGebra-based learning has a better value than students given Non-GeoGebra learning, students with high motivation and medium motivation have better spatial abilities than students with low motivation. Students with high motivation and medium motivation categories have the same influence on their spatial abilities. Furthermore, there is no interaction between GeoGebra based learning and motivation on students' spatial abilities.
\end{abstract}

Keywords: GeoGebra, Motivation, Spatial ability.

\section{Introduction}

The rapid development of science and technology now turns out to be comprehensive in all fields of human life is no exception in the field of education. Moreover, the demands of modern times are increasingly complex, the field of education needs serious handling. According to the Kamus Besar Bahasa Indonesia (KBBI), education is the process of changing the attitudes and behavior of a person or group of people in an effort to mature humans through teaching and training efforts. Education plays a very important role in human survival. The education process is an activity of mobilizing all components of education that are directed towards the achievement of educational goals. How the education process is carried out will determine the quality of the achievement of educational goals.

The purpose of national education according to Law No.20 of 2003 concerning the national education system which states that "National education functions to develop the ability and shape the character of the nation's dignified dignity in order to educate the life of the nation, aims to develop the potential of students to become human beings who believe and have faith to God Almighty, noble, healthy, knowledgeable, capable, creative, independent and be a citizen of democracy and responsibility". 
Today, almost every company conducts a psychological test as one of the stages that must be passed when applying for work. One of the tests that is usually given is the spatial ability test. In general, the ability required in this test is more on the ability to analyze the shape of the image, image reflection, and comparison of images with one another. Spatial ability is also one of the abilities measured in the Tes Potensi Akademik (TPA) which is usually used in Saringan Bersama Masuk Perguruan Tinggi Negeri (SBMPTN) and Penelusuran Minat dan Kemampuan (PMDK). SBMPTN is a form of student admission selection pathway to enter state universities which are carried out simultaneously in coordination with the Central Committee. While PMDK is an entry point organized by each university or certain institute to screen students who have talent and superior academic ability compared to prospective students.

The national average TPA value is 500 and the average TPA for scholarship recipients (1997, 1998 and 1999) is 550. The minimum TPA value range for passing the S2 selection filter is 450-500 and passing the S3 selection filter is 550-600. For new lecturers, to obtain NIDN (National Lecturer Registration Number), the lowest TPA is 530.

From interviews with teachers in Vocational High School in Subang in the 2016 or 2017 school year, there were only three students who passed PMDK Mandiri. This is because differences in student's spatial ability level. Students have difficulty in solving problems related to spatial abilities, especially if faced with objects with two and three dimensions. They have difficulty in making relationships between objects in fields and spaces, and they also have difficulty imagining and describing problems in the form of images. Another factor that is an obstacle is the difference in student motivation, this can be seen during the learning process, some students are very active in following the lessons, some others seem mediocre, while the rest tend to be passive.

Humans have a basic set of intelligence [1]. Multiple intelligence, including logicalmathematical intelligence, verbal-linguistic intelligence, visual-spatial intelligence, musical intelligence, kinesthetics' intelligence, emotional intelligence, naturalist intelligence, intuitive intelligence, moral intelligence, existential intelligence, spiritual intelligence [2]. Spatial intelligence is one of 8 multiple intelligences. According to Gardner[3], spatial intelligence is the ability to perceive the spatial world accurately. Spatial ability is an intellectual psychological factor while motivation is a non-intellectual psychological factor that greatly influences students' desires to participate in learning activities. Spatial ability and motivation of these students can be increased by providing approaches, methods and appropriate media during their learning. Arbain[4] said that students have a positive perception of learning and have better learning achievement using GeoGebra. GeoGebra can benefit students in Mathematics learning and diversifying learning in classrooms. The overflown of resources triggered students' interest to learn Mathematics however, the selection of software has to be properly planned.

GeoGebra is a computer program (software) that can be used as an interactive learning media. GeoGebra allows students to be active in building an understanding of geometry. GeoGebra can also provide visualizations of geometrical concepts. According to Putz[5], students who use GeoGebra will understand geometry more deeply because there is a clear visual representation of objects in geometry and student involvement to construct so students understand geometry more deeply.

Computer and Network Engineering (TKJ) is one of the expertise programs found in Vocational High School. In accordance with their interests and majors in the field of Information and Communication Technology, students of 12th grade have the potential to use computers in learning. This potential can certainly be empowered positively for mathematics learning.

Based on the description above to find appropriate and efficient learning strategies to improve the spatial ability and learning motivation of students of 12 th grade, the researcher 
wants to apply GeoGebra-based learning in studying geometry transformation. GeoGebra can reduce the abstractness of geometric concepts and visualize these concepts in concrete form. The use of GeoGebra in learning Geometry Transformation will make it easier to understand Translations, Reflections, Rotations, and Dilations.

According to Mahmudi[6] the excess utilization of GeoGebra, (1) Geometry paintings that are usually produced quickly and thoroughly compared to using a pencil, ruler, or term, (2) The existence of animation facilities and manipulation movements (dragging) on the GeoGebra program can provide clearer visual experiences for students in understanding the concept of geometry, (3) Can be used as feedback/evaluation to ensure that the paintings that have been made are correct, and (4) Make it easier for teachers/students to investigate or show the properties that are applied to a geometry object.

From the description above, it is suspected that GeoGebra-based learning can enhance the students' spatial ability and students' motivation.

\section{Methods}

The research method used in this research is the Quasi Experiment. The design used in this study is two-way Anova. The population in this study were all students of 12th grade in public vocational secondary high school which was divided into 20 classes. Samples were taken by purposive sampling. The sample in this study amounted to 60 students consisting of class 12th TKJ 1 with a total of 30 students and class 12 th TKJ 2 with a total of 30 students.

One of the classes is an experimental class (XII TKJ 2), a class that receives GeoGebrabased learning and the other class as a control class (XII TKJ 1), which is a class that receives Non-GeoGebra learning. Mathematics topics in the teaching experiment are Geometry Transformation.

The instruments used in this study were: learning motivation questionnaire and spatial ability test. The measurement of spatial ability in this study is focused on classical or group measurements. Spatial ability tests generally aim to measure the power of visual logic, spatial imagination, accuracy and accuracy of a person presented in the form of images or abstract symbols[7]. This study uses one of the popular spatial ability tests, Spatial Ability Practice Test 1, which was made by Newton and Bristoll[8].

\section{Result and Discussions}

\subsection{Findings}

The following are the results of research on students' motivation in learning mathematics as presented in Table 1 .

Table 1. Descriptive Statistics Motivation Score for Experimental Group and Control Group.

\begin{tabular}{lcccc}
\hline Test Result & Min & Max & Ave & SD \\
\hline Experiment Group & 82 & 142 & 108.57 & 15.68 \\
Control Group & 70 & 139 & 99.87 & 19.99 \\
\hline
\end{tabular}


Based on Table 1 it can be obtained that the average score of students' learning motivation in the control class is 99.87 with a standard deviation of 19.993 which means that the absolute deviation of data against an average value of 19.993. Based on Table 1, it can be obtained that the average score of students' learning motivation in the Experiment class is 108.57 with a standard deviation of 15.677 which has the meaning that the absolute deviation of data against an average value of 15.677 .

The frequency distribution of student motivation can be visualized in the form of a histogram below:

Based on Figure 1 we found that students in the control group and experimental group most obtained learning motivation scores in the range 94-105. It can be defined that students' learning motivation in mathematics subjects is in the low and medium category because the range is still below the average of the learning motivation score.

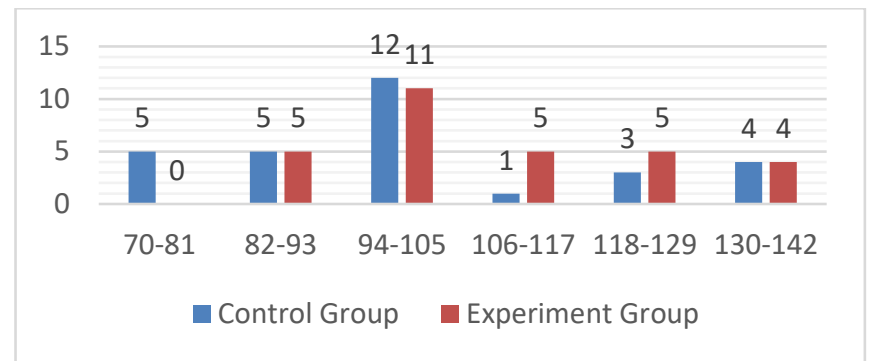

Fig. 1. Histogram Comparison of Student Learning Motivation Scores Between Experimentation Class and Control Class

From Table 2 we can see that students who were given GeoGebra-based learning in geometry transformation showed an average of 79.10 with a standard deviation of 8.277 which means that the absolute deviation of the data against the average was 8.277. The lowest and highest grades obtained by students in the experiment group are 64 and 91, and a large variance of 68.507 .

Table 2. Student's Mathematical spatial abilities under GeoGebra-based learning.

\begin{tabular}{lllll}
\hline Test Result & Min & Max & Ave & SD \\
\hline Experiment Group & 64 & 91 & 79.1 & 8.28 \\
Control Group & 60 & 91 & 76.27 & 8.83 \\
\hline
\end{tabular}

From Table 3 , it can be seen the average value of spatial ability based on the level of motivation and GeoGebra-based learning that the average value of spatial ability with a high level of motivation and GeoGebra-based learning is 82.91. The average value of spatial ability with a medium level of motivation and GeoGebra-based learning is 79.20. The average value of spatial ability with low motivation and GeoGebra based learning is 68.25. While the average value of spatial ability with a high level of motivation and Non-GeoGebra-based learning is 82.00. The average value of spatial ability with medium motivation and Non-GeoGebra based learning is 78.38 and the average value of spatial ability with low motivation and Non-GeoGebra based learning is 68.11. 
Tabel 3. Interaction between GeoGebra-based Learning and Motivation on students' spatial abilities.

\begin{tabular}{cccc}
\hline Level of Motivation & Learning Software & Mean & Std Deviation \\
\hline \multirow{2}{*}{ Low } & Geogebra & 68.25 & 5.679 \\
& Non-geogebra & 68.11 & 7.236 \\
Medium & Geogebra & 79.20 & 7.939 \\
& Non-geogebra & 78.38 & 7.698 \\
\multirow{2}{*}{ High } & Geogebra & 82.91 & 6.139 \\
& Non-geogebra & 82.00 & 5.477 \\
\hline
\end{tabular}

The following task provides additional evidence that students sometimes experience difficulty in imagining the manipulation, rotation, loop, feedback of an object (spatial visualization) and integrate information relating to natural or artificial objects in their environment (environmental ability).

In Figure 2 we can see that students' have the wrong answer for the question about spatial relation and environmental ability. They solve the problem with scratches and fold the paper, but still not have the right answer. After student learning by GeoGebra, they can choose the right answer for that question.

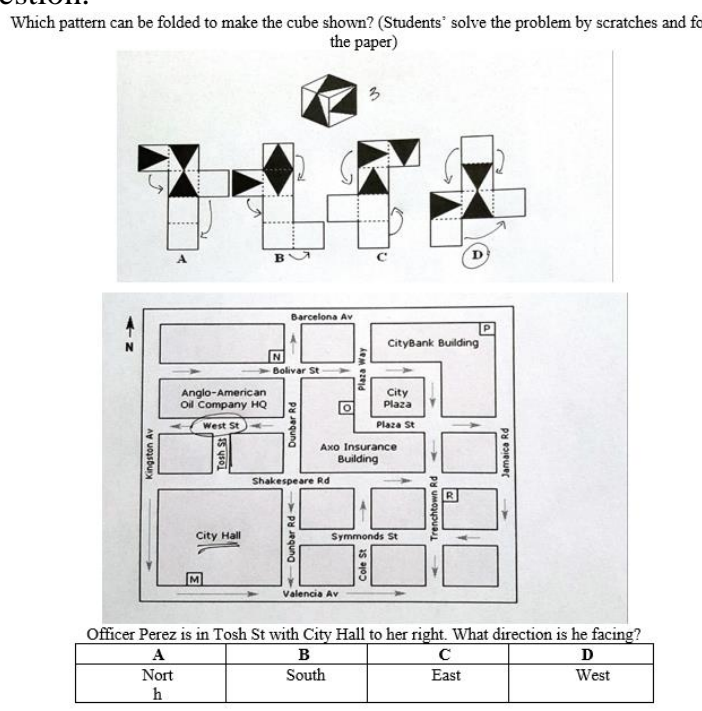

Fig. 2. Example of students' spatial ability answer (PreTest).

\subsection{Differences between the application of GeoGebra-based learning and Non- GeoGebra on the spatial abilities of students in Geometry Transformation}

There is no difference in effect between the application of GeoGebra-based learning and Non-GeoGebra on that is applied to students' spatial abilities. Nevertheless, the experimental class obtained the results of a higher spatial ability than the control class. To test mathematics learning based on GeoGebra and Non-GeoGebra, learning was held three times in each class. After that, the evaluation with 36 items tests to measure the spatial ability of students. Student 
test results in the experimental class obtained an average value of 79.10 and the average value in the control class was 76.27.

Based on data analysis, there is no significant difference, this can be caused by several factors both factors that are controlled in the study and other factors outside the study that cannot be controlled. Some factors outside the experiments that become obstacles when the research takes place include the behavior of students who are somewhat difficult to control when discussing, this causes the time that should be used maximum to discuss when learning in class using GeoGebra media less than that. In Figure 3 we can see an example of how the GeoGebra was used in the teaching process.

Observations found in the experimental class from Figure 4 when learning GeoGebra based on some groups dominated by someone, so that some students tend to be passive and rely on their groups. Therefore, the interaction between students in the group when GeoGebra-based learning is done is felt to be less than optimal.

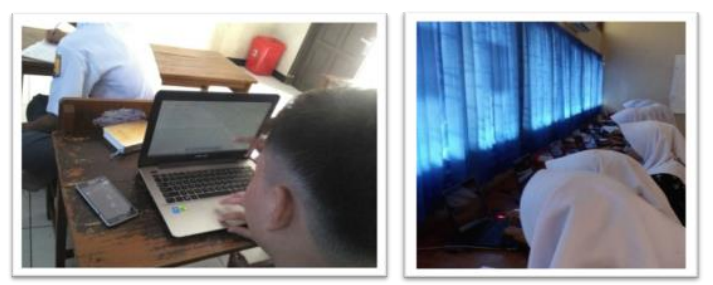

Fig. 3. Students' Use GeoGebra Software in Experiment Class

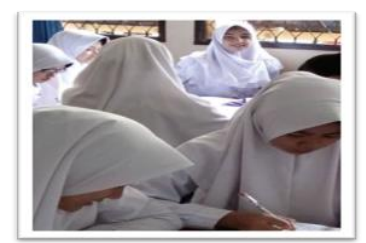

Fig. 4. Students' Discussion in Experiment Class

During research, students have limited time when completing assignments, whereas GeoGebra-based learning is designed to improve student constructivism by working on existing projects. With time constraints that occur then at some project meetings held outside of class hours which this makes it difficult to control the students when working on given tasks.

Although there is no positive and significant influence, it is found that the average difference in the value of spatial abilities between groups of students who are subject to learning based on GeoGebra and Non-GeoGebra. The average spatial ability in classes with GeoGebra based learning is higher than classes with Non-GeoGebra learning. The results of the spatial ability of the experimental class obtained an average of 79.10 higher than the spatial ability of the control class which averaged 76.27.

The use of GeoGebra gives a slightly better spatial ability results because students explore from the worksheet given by the teacher using the GeoGebra program. The procedure for implementing GeoGebra-based learning in this study is to design learning plans and worksheets, arrange schedules, monitor students, test results, and evaluate. GeoGebra-based learning is an effort to trigger motivation and enthusiasm for learning and discover concepts that would be the goal of learning geometry transformation with the help of GeoGebra-based learning media. For 
Non-GeoGebra learning students are indeed required to be more active and independent in thinking, but students must be active by finding and investigating themselves to find concepts that would be the goal of learning geometry transformation without the help of GeoGebra-based learning media.

\subsection{Difference between learning motivation categories and students' spatial ability}

There are differences between learning motivation categories and students' spatial ability in learning geometry transformation. The results obtained that the number of students from both classes are 19 students for the high motivation level, 28 students for the medium motivation level, and 13 students with low motivation level. The average score of motivation in the high level is 82.526 , for the average score of motivation in the medium level is 78.821 , and the lowest average score is 68.15 . The test results show that the value $F=14.550$ with Sig. $=0.000(<0.05)$ then the hypothesis is rejected, this means that there are differences between the three-level of student learning motivation towards geometry transformation on their spatial ability. These differences can be seen in the results of Anava analysis which shows whether there are differences between the three-level of learning motivation, namely high, medium, and low on students' spatial ability. However, in this case, it cannot be identified which level is different. To find out the differences between groups, a post-Anava further test was conducted with the Tukey test. The results obtained indicate that the significance value of high motivation and low motivation level $=0,000$, the significance value of high and medium motivation level $=0.191$, and the significance value for medium and low level $=0,000$. The hypothesis is accepted if the value of significance $>0.05$ and the hypothesis is rejected if significance $<0.05$. This means that the average increase in students' spatial ability in the level of high and low motivation and medium and low motivation very different. As for the average increase in the spatial ability of students for the high and medium categories, there is no significant difference.

Based on observations, students with high motivation tend to dominate more when learning. Students with high motivation are active when learning both in the experimental and control classes. The students always ask questions with explanations that are difficult to understand, and when discussions take place students with high motivation almost dominate the discussion. In contrast to students with low motivation, students with low motivation tend to use less time, this is indicated by some students use it for games instead of using computers for the GeoGebra program. Students with low motivation tend not to concentrate on the explanation and giving no questions when learning, some students tend to depend on the group. So, it looks very different behavior in students with low and high motivation. Where this has a positive and significant effect on the value of spatial ability, students with high learning motivation get higher spatial ability scores while students with low learning motivation tend to get more low spatial ability.

\subsection{Interaction between GeoGebra based learning and motivation on students' spatial abilities}

From the data that has been analyzed, the interaction between GeoGebra based learning and motivation on students' spatial abilities. The results of the analysis show that $F=0.012$ with Sig. $=0.988(>0.05)$, then the hypothesis is accepted, this means that there is no difference between GeoGebra based learning and motivation on students' spatial abilities. Students with high motivation have no tendency to get better spatial abilities using GeoGebra and NonGeoGebra learning media. It also occurs in the level of medium motivation and low motivation, 
there is no tendency to get better spatial abilities using GeoGebra-based learning and NonGeoGebra. Students with high learning motivation in each of the experimental and control classes always dominate, they are always active when learning both in class using GeoGebrabased learning and Non-GeoGebra learning. Observations during learning show that the course of discussion in the GeoGebra class is mostly dominated by students with high motivation levels, which is not much different that occurs during Non-GeoGebra class discussions.

\section{Conclusion}

Based on the data collected by researchers in the field and the analysis conducted by researchers, several conclusions can be drawn, namely: 1) There is no difference in differences between the application of GeoGebra-based learning and Non-GeoGebra on the spatial abilities of students in Geometry Transformation; 2) Students with high motivation and medium motivation level have better spatial ability than students with low motivation level. Each level has a different average spatial ability, for the level of high motivation and low motivation as well as medium motivation and low motivation different significantly. As for the average spatial ability of students in the high motivation and medium motivation, there is no significant difference in the average; 3 ) The interaction of students 'learning motivation and learning media does not have a significant influence on students' spatial ability. There are several limitations of the study, 1) students have limited time when completing assignments; 2) some groups dominated by someone so that some students tend to be passive and rely on their groups.

\section{Reference}

[1] Gardner, H.: (Multiple intelligences after twenty years. American Educational Research Association, Chicago, Illinois, 21,pp. 1-15 (2003)

[2] Feldhusen, J. F., \& Hoover, S. M.: A conception of giftedness: Intelligence, self concept and motivation. Roeper Review, 8(3), pp. 140-143 (1986)

[3] H. Gardner.: "The theory of multiple intelligences," Ann. Dyslexia, vol. 37, no. 1, pp. 19-35, (1987)

[4] N. Arbain, N. A. Shukor.: "The Effects of GeoGebra on Students Achievement," Procedia - Soc. Behav. Sci., vol. 172, no. 2007, pp. 208-214, (2015)

[5] Pütz, C. : Teaching Descriptive Geometry: Principles and Effective Methods Demonstrated by the Example of Monge Projection. XV Conference on Graphics, Sao Paulo Brazil, November 5-9, (2001)

[6] A. Mahmudi: Pemanfaatan Geogebra dalam Pembelajaran Matematika. Semin. Nas. Mat. dan Pendidik. Mat., pp. 10-19 (2011)

[7] Yilmaz, H. B.: On the development and measurement of spatial ability. International Electronic Journal of Elementary Education, 1(2), 83-96. (2017)

[8] C. Burt.: Spatial Ability. Br. J. Math. Stat. Psychol., vol. 18, no. 2, pp. 257-259, (1965) 